\title{
Important drug classes associated with potential drug-drug interactions in critically ill patients: highlights for cardiothoracic intensivists
}

\author{
Shadi Baniasadi ${ }^{1}$, Behrooz Farzanegan ${ }^{2}$ and Maryam Alehashem²*
}

\begin{abstract}
Background: Patients in the intensive care unit (ICU) are more prone to drug-drug interactions (DDIs). The software and charts that indicate all interactions may not be proper for clinical usage. This study aimed to identify the main drug classes associated with clinically significant DDIs in cardiothoracic ICU and categorize DDIs to make cardiothoracic intensivists aware of safe medication usage.

Methods: This prospective study was conducted over 6 months in a cardiothoracic ICU of a university-affiliated teaching hospital. The presence of potential drug-drug interactions (pDDIs) was assessed by a clinical pharmacologist using Lexi-Interact database. Clinically significant pDDIs were defined according to severity and reliability rating. Interacting drug classes, mechanisms, and recommendations were identified for each interaction.

Results: From 1780 administered drugs, 496 lead to major (D) and contraindicated (X) interactions. Nine drug classes were responsible for $D$ and/or $X$ interactions with excellent (E) and/or good (G) reliability. Anti-infective agents $(45.87 \%)$ were the main drug classes that caused clinically significant pDDls followed by central nervous system drugs (14.67\%). Azole antifungals as the most interacting antimicrobial agents precipitated metabolism inhibition of CYP3A substrates.

Conclusions: Clinically significant pDDIs as potential patient safety risks were prevalent in critically ill patients. The findings from current study help to improve knowledge and awareness of clinicians in this area and minimize adverse events due to pDDIs.
\end{abstract}

\section{Background}

Drug-drug interactions (DDIs) are a growing concern in all clinical settings, particularly intensive care units (ICUs) [1]. ICU-admitted patients are at an increased risk of DDIs due to the complexity of pharmacotherapy, large number of medications, disease severity, and organ failure [2-5]. DDIs are common causes of adverse drug events that may affect patient health; therefore, the identification and prevention of potential drug-drug

\footnotetext{
*Correspondence: maryamalehashem@yahoo.com

${ }^{2}$ Tracheal Diseases Research Center, National Research Institute of Tuberculosis and Lung Diseases (NRITLD), Shahid Beheshti University of Medical Sciences, Tehran, Iran

Full list of author information is available at the end of the article
}

interactions (pDDIs) could improve patient safety [6]. Since it would be impossible for any physician to remember all pDDIs, improving the knowledge of clinical practitioners in terms of clinically important DDIs could reduce the risk of serious adverse outcomes. Applying DDI software and employing clinical pharmacists to detect and prevent DDIs have improved patient safety in advanced countries [1,7], while physicians in developing countries still identify DDIs based on their own experiences $[8,9]$.

Previous studies regarding pDDIs have focused on frequency, type, mechanisms, severity, drug combinations, management and related outcomes in ICU settings [1, 10-14], but important drug classes involved in 
well-documented and severe pDDIs in cardiothoracic ICU have not yet been reported. Therefore, the current study aimed to highlight the main drug classes associated with clinically important DDIs. The results of this study could increase knowledge among intensivists (especially cardiothoracic intensivists) in the context of DDI prevention and safe medication usage.

\section{Methods}

\section{Study design and protocol}

This cross-sectional study was conducted at Masih Daneshvari Hospital, a university-affiliated hospital for lung diseases, over a 6-month period. The study protocol was approved by the hospital's ethical review board. Data related to the pharmacotherapy of the subjects were assessed $48 \mathrm{~h}$ after admission to an 8-bed surgical cardiothoracic ICU by a clinical pharmacologist using LexiInteract database, a complete drug and herbal interaction analysis program. The software identifies interacting drugs, mechanisms, severity, reliability (documentation) rating $(E=$ excellent, $G=$ good, $F=$ fair), potential outcomes, and clinical management. According to severity, the interactions are categorized into five categories: A (unknown), B (minor), C (moderate), D (major), and $\mathrm{X}$ (contraindicated) [15]. Drugs involved in pDDIs and subjects' diagnoses were classified according to AHFS Drug Information [16] and International Classification of Diseases (ICD10), respectively [17]. At the time of admission, any home medication, herbal medication, and nutritional supplements were stopped according to the ICU policy. Hydro-electrolytic components, insulin, water-soluble vitamins, and topical drugs were excluded from further analysis. Physicians were notified of interactions that might lead to alterations in drug therapy.

\section{Data analysis}

Data were analyzed using descriptive statistics from the SPSS software v.22.0 for Windows (SPSS, Chicago, IL). The median, range, and percentage were applied to present the results where appropriate. The interacting drug classes, significance, reliability, and clinical management of the interactions were recorded in a database. Interactions with a severity rating of $\mathrm{D}$ and/or $\mathrm{X}$ and a reliability rating of $\mathrm{E}$ and/or $\mathrm{G}$ were considered clinically important pDDIs for more analysis.

\section{Results}

Overall, 195 prescriptions were evaluated over the 6 -month study period. Table 1 shows the demographic and clinical characteristics of the subjects. The average length of stay in ICU was 5 days. Total administered and interacting medications ( $\mathrm{D}$ and $\mathrm{X}$ interactions with any documentation rating) were 1780 and 496, respectively
(Table 2). $\mathrm{D}$ and/or $\mathrm{X}$ interactions were identified in $37.94 \%$ (74) of the prescriptions. Of the 248 pDDIs with a severity rating of $\mathrm{D}$ and/or $\mathrm{X}, 157$ were unique drug pairs (a specific combination of interacting medication that is counted one time). The drug classes and specific medications involved in $\mathrm{D}$ and/or $\mathrm{X}$ interactions are shown in Table 3. The drug pairs causing $\mathrm{D}$ and/or $\mathrm{X}$ interactions with $\mathrm{E}$ and/or G reliability are displayed in Table 4.

\section{Discussion}

The present study evaluated clinically important pDDIs in terms of drug classes, mechanisms, and recommendations in the cardiothoracic ICU. Scientifically, important measures to decrease the risk of DDIs are computerized prescribing, pharmacotherapy monitoring, and pharmacist participation in the multidisciplinary team [18]. Where these services are not available (e.g., due to budget shortages), continued education and expert studies on pDDIs could improve patient safety. Software that identifies a large number of DDIs with any rating of severity and reliability could result in a lack of attention given to the warnings [19]. Categorizing DDIs by drug classes and highlighting more severe and reliable interactions may increase the tendency of clinicians to prevent clinically significant DDIs.

Results of the current study revealed that anti-infective, central nervous system (CNS), and cardiovascular agents were the main drug classes involved in $\mathrm{D}$ and X pDDIs. Antimicrobials were the most administered medications in the studied setting and were responsible for a high number of pDDIs. Anti-infective agents are commonly used in the ICU and are associated with clinically significant interactions [20]. Antithrombotic agents and cardiovascular drugs are usually reported as the most common interacting drug groups in ICU settings [1, 10-12]. Different results may be related to the inclusion of moderate and/or not well-documented pDDIs in other studies. These authors' previous study also showed that antibiotics were the most commonly implicated drug class for adverse drug reactions [21]. Overestimated usage of antibiotics is an important issue in developing countries where the use of antibiotics requires close monitoring to ensure effective treatment and, ultimately, cost reduction [22].

A wide range of different consequences could be predicted according to DDIs mechanisms. The altered gastrointestinal (GI) absorption of antibiotics and the inhibition/induction of drug metabolizer enzymes are the mechanisms most often associated with antimicrobial interactions [20,23]. The inhibition of metabolism by azole antifungal agents (most interacting drugs in the current study) may lead to increased tacrolimus and cyclosporine concentrations in transplant 
Table 1 Demographic and clinical characteristics of the patients

\begin{tabular}{|c|c|}
\hline Characteristics & \\
\hline Number of patients $(n)$ & 184 \\
\hline Age [median (range)] & $48(3-85)$ \\
\hline Gender (male/female) & $110 / 74$ \\
\hline Number of prescriptions $(n)$ & 195 \\
\hline Number of prescriptions including: & \\
\hline $1-8$ drugs $(n)$ & 110 \\
\hline $9-17$ drugs $(n)$ & 71 \\
\hline $18-25$ drugs $(n)$ & 14 \\
\hline Diagnoses classification (n) & \\
\hline Certain infectious and parasitic diseases & 7 \\
\hline Neoplasms & 43 \\
\hline Diseases of the blood and blood-forming organs and certain disorders involving the immune mechanism & 1 \\
\hline Diseases of the circulatory system & 32 \\
\hline Diseases of the respiratory system & 68 \\
\hline Diseases of the digestive system & 6 \\
\hline Congenital malformations, deformations and chromosomal abnormalities & 6 \\
\hline Symptoms, signs and abnormal clinical and laboratory findings, not elsewhere classified & 1 \\
\hline Injury, poisoning and certain other consequences of external causes & 4 \\
\hline Factors influencing health status and contact with health services & 16 \\
\hline
\end{tabular}

Table 2 The number and percentages of total administered and interacting drugs in different drug classes

\begin{tabular}{|c|c|c|c|}
\hline Drug classes & $\begin{array}{l}\text { Total administered } \\
\text { drugs } \%(n)\end{array}$ & $\begin{array}{l}\text { D and/or } X \text { interacting } \\
\text { drugs } \%(n)\end{array}$ & $\begin{array}{l}\text { D and/or } X \text { interacting precipitant } \\
\text { drugs with } E \text { and/or } G \text { reliability } \%(n)\end{array}$ \\
\hline Anti-infective agents & $22.35 \%(398)$ & $25.00 \%(124)$ & $45.87 \%(50)$ \\
\hline Central nervous system agents & $20.50 \%(365)$ & $19.95 \%(99)$ & $14.67 \%(16)$ \\
\hline Cardiovascular drugs & $19.21 \%(342)$ & $13.10 \%(65)$ & $5.50 \%(6)$ \\
\hline Gastrointestinal drugs & $12.80 \%(228)$ & $6.65 \%(33)$ & $4.58 \%(5)$ \\
\hline Hormones and synthetic substitutes & $6.68 \%(119)$ & $11.29 \%(56)$ & $2.75 \%(3)$ \\
\hline Respiratory tract agents & $6.40 \%(114)$ & $3.22 \%(16)$ & - \\
\hline Electrolytic, caloric, and water balance & $5.33 \%(95)$ & $6.65 \%(33)$ & $10.09(11)$ \\
\hline Blood formation, coagulation, and thrombosis & $2.07 \%(37)$ & $3.42 \%(17)$ & $3.67 \%(4)$ \\
\hline Autonomic drugs & $2.02 \%(36)$ & $3.02 \%(15)$ & $9.17 \%(10)$ \\
\hline Miscellaneous therapeutic agents & $2.02 \%(36)$ & $7.05 \%(35)$ & $3.66 \%(4)$ \\
\hline Vitamins & $0.56 \%(10)$ & $0.60 \%(3)$ & - \\
\hline Total & 1780 & 496 & 109 \\
\hline
\end{tabular}

patients and the increased toxicity of these medications [24]. On the other hand, metabolism induction usually results in decreased clinical efficacy of other drugs instead of adverse effects. Quinolones and macrolides (with torsadogenic potential) may interact synergically with other medications and result in QTc prolongation and torsades de pointes [25]. It was also found that these mechanisms play the main role in anti-infective interactions that could be managed by adjusting drug administration time, and dosage, or using an alternative medication $[23,25]$.
CNS drugs were 20.50 and $19.95 \%$ of administered medications and interacting drugs, respectively. These medications are frequently used to control seizures, pain, and anxiety and to treat delirium, depression, and psychotic symptoms in ICU settings [26]. A conducted study in a mixed ICU showed that $40 \%$ of the pDDIs were associated to drugs acting on CNS [27]. In the current study, $14.67 \%$ of $\mathrm{D}$ and/or X pDDIs with reliability ratings of $\mathrm{E}$ and/or $\mathrm{G}$ were related to these agents as a precipitant drug. Carbamazepine was the most frequent CNS drug that interacted with CYP3A substrates (such 
Table 3 Drug classes, specific medications associated with D and/or X interactions, and the frequency of interactions

\begin{tabular}{|c|c|}
\hline Drug classes (frequency of interactions) & Specific medications (frequency of interactions) \\
\hline Anti-infective agents (124) & $\begin{array}{l}\text { Itraconazole (24), Ciprofloxacin (17), Voriconazole (16), Rifampin (14), Clarithromycin (11), Erythro- } \\
\text { mycin (10), Dapsone (7), Co-trimoxazole (5), Levofloxacin (4), Posaconazole (4), Meropenem (3), } \\
\text { Ofloxacin (3), Isoniazid (2), Pyrazinamide (1), Lamivudine (1), Valganciclovir (1), Caspofungin (1) }\end{array}$ \\
\hline Central nervous system agents (99) & $\begin{array}{l}\text { Carbamazepine (20), Phenytoin (16), Fentanyl (11), Midazolam (10), Haloperidol (8), Valproic acid } \\
\text { (5), Indomethacin (5), Quetiapine fumarate (4), Citalopram (4), Risperidone (2), Imipramine (2), } \\
\text { Clonazepam (2), Methadone (2), Lorazepam (1), Chlorpromazine (1), Celecoxib (1), Diclofenac (1), } \\
\text { Fluvoxamine (1), Alprazolam (1), Clomipramine (1), Carbidopa and Levodopa (1) }\end{array}$ \\
\hline Cardiovascular drugs (65) & $\begin{array}{l}\text { Atorvastatin (19), Metoprolol (10), Losartan (6), Amiodarone (6), Amlodipine (4), Diltiazem (4), Cap- } \\
\text { topril (3), Sildenafil (2), Carvedilol (2), Furosemide (2), Digoxin (2), Propranolol (1), Dabigatran (1), } \\
\text { Heparin (1), Enalapril (1), Gemfibrozil (1) }\end{array}$ \\
\hline Hormones and synthetic substitutes (56) & $\begin{array}{l}\text { Dexamethasone (33), Prednisolone (9), Methylprednisolone (6), Levothyroxine (4), Hydrocortisone } \\
\text { (3), Octreotide (1) }\end{array}$ \\
\hline Miscellaneous therapeutic agents (35) & Cyclosporine (15), Tacrolimus (10), Mycophenolate (6), Tamsulosin (3), ALLOPURINOL (1) \\
\hline Electrolytic, caloric, and water balance (33) & $\begin{array}{l}\text { Calcium carbonate (16), Magnesium sulfate (5), Sodium polystyrene sulfate (4), Calcium gluconate } \\
\text { (3), Sodium phosphate (2), Spironolactone (1), Zinc sulfate (1), Potassium chloride (1) }\end{array}$ \\
\hline Gastrointestinal drugs (33) & $\begin{array}{l}\text { Pantoprazole (19), Granisetron (8), Ranitidine (3), Metoclopramide (1), Omeprazole (1), Aluminum, } \\
\text { Magnesium hydroxide (1) }\end{array}$ \\
\hline Blood formation, coagulation, and thrombosis (17) & Warfarin (6), Clopidogrel (4), Ferrous sulfate (4), Acetylsalicylic acid (3) \\
\hline Respiratory tract agents (16) & Ipratropium (7), Formoterol (3), Fluticasone (3), Salbutamol (2), Theophylline (1) \\
\hline Autonomic drugs (15) & Atracurium (9), Tizanidine (2), Prazosin (2), Cisatracurium (1), Epinephrine (1) \\
\hline Vitamins (3) & Calcitriol (3) \\
\hline
\end{tabular}

as phenytoin, clonazepam, and warfarin). Monitoring the therapeutic effects of object drugs and considering an alternative medication (if possible) are recommended as appropriate interventions [28]. In addition to metabolism, additive and antagonistic effects were the main mechanisms for CNS drug interactions in this study.

Electrolytic, caloric, and water balance agents, which include metal ions, accounted for $10.09 \%$ of clinically important pDDIs. Metal ions form complexes with other medications, especially antimicrobial agents, and affect drug absorption. A reasonable recommendation is to administer oral medications at least $1-2 \mathrm{~h}$ before, and not within $4 \mathrm{~h}$ after, administering the metal ions [23].

In autonomic drug classes, the combination of neuromuscular blocking agents and corticosteroids may lead to further risk of prolonged muscle weakness, including neuropathy, myopathy, and/or paralysis. This has been observed most commonly in the ICU setting, particularly in patients requiring high doses of intravenous steroids [29]. It is recommended to monitor for new onset or worsening of adverse neuromuscular effects and to use a neuromuscular blocking drug only when absolutely necessary [30]. Corticosteroids were administered commonly for tracheal stenosis (15.2\%) and COPD (4.3\%) in the studied setting. After that, neoplasms (23.4\%) and transplants $(8.7 \%)$ were the most common indications for corticosteroid administrations.

Although "cardiovascular" and "blood formation, coagulation, and thrombosis" agents accounted for $21.28 \%$ of administered medications and $16.52 \%$ of interacting drugs, only $9.17 \%$ of well-documented D and/or X interactions were related to these groups as precipitant drugs. As mentioned above, pDDIs were classified according to the object and precipitant drugs. In $18.35 \%$ of pDDIs, the drugs belonging to these groups were object drugs. Documentation rating was considered to highlight clinically important pDDIs. A high number of interactions caused by these drug classes were rated as fair documentation. Amiodarone (a CYP2D6 inhibitor) should be considered as a precipitant drug with a large number of interactions. Considering an alternative for one of the interacting agents and monitoring responses are usually recommended [31].

Proton pump inhibitors (PPIs) and histamine-2 receptor antagonists $\left(\mathrm{H}_{2} \mathrm{RAs}\right)$ are routinely used for critically ill subjects who are at high risk for stress-related mucosal damage (SRMD) [32]. The pH-raising effect of these GI drugs may decrease absorption and the serum concentration of azole antifungal agents (itraconazole, voriconazole, and posaconazole). Use of the azoles oral solutions (instead of capsule) or administration of the azoles with an acidic beverage could minimize the significance of this interaction [33]. Variations in practices and medications between ICU settings may lead to different pDDIs patterns [1]. Proton pump inhibitors are administered in the currently studied setting to patients with a history of GI disorders, major surgeries, and anticoagulant usage. Although there is lack of firm evidence that PPI reduces 
Table 4 Drug classes, precipitant and object drugs, mechanisms and recommendations for clinically significant pDDIs

\begin{tabular}{|c|c|c|c|c|}
\hline Drug classes & $\begin{array}{l}\text { Precipitant } \\
\text { drugs }^{\text {a }}\end{array}$ & Object drugs $^{a}$ & Mechanisms & Recommendations \\
\hline \multirow{30}{*}{$\begin{array}{l}\text { Anti-infective } \\
\text { agents }\end{array}$} & \multirow[t]{6}{*}{ Itraconazole } & Tacrolimus & Metabolism (inh) & Monitor tacrolimus concentration \\
\hline & & Diltiazem & Metabolism (inh) & Monitor diltiazem toxic effects \\
\hline & & Digoxin & Absorption & Monitor digoxin concentration \\
\hline & & Atorvastatin & Metabolism (inh) & Reduce dose, monitor toxic effects \\
\hline & & Clarithromycin & Metabolism (inh) ${ }^{b}$ & Monitor toxic effect of clarithromycin/itraconazole \\
\hline & & Methylprednisolone & Metabolism (inh) & Reduce dose, monitor corticosteroid toxicity \\
\hline & \multirow[t]{6}{*}{ Voriconazole } & Tacrolimus & Metabolism (inh) & Reduce dose, monitor tacrolimus concentration \\
\hline & & Cyclosporine & Metabolism (inh) & Reduce dose, monitor cyclosporine concentration \\
\hline & & Diltiazem & Metabolism (inh) & Monitor diltiazem toxic effects \\
\hline & & Methylprednisolone & Metabolism (inh) & Reduce dose, monitor corticosteroid toxicity \\
\hline & & Methadone & Metabolism (inh) & Monitor methadone toxic effects \\
\hline & & Midazolam & Metabolism (inh) & Monitor midazolam toxic effects \\
\hline & \multirow[t]{5}{*}{ Ciprofloxacin } & Theophylline & Metabolism (inh) & Reduce dose, monitor theophylline toxic effects \\
\hline & & Erythromycin & Additive & Avoid combination \\
\hline & & Formoterol & Additive & Avoid combination \\
\hline & & Granisetron & Additive & Avoid combination \\
\hline & & Voriconazole & Additive & Avoid combination \\
\hline & \multirow[t]{5}{*}{ Rifampin } & Itraconazole & Metabolism (ind/inh) ${ }^{b}$ & Avoid combination/monitor for clinical response to itraconazole \\
\hline & & Clarithromycin & Metabolism (ind/inh) ${ }^{b}$ & $\begin{array}{l}\text { Monitor for clarithromycin therapeutic effects/rifampin toxic } \\
\text { effects }\end{array}$ \\
\hline & & Cyclosporine & Metabolism (ind) & $\begin{array}{l}\text { Consider an alternative, monitor cyclosporine serum concentra- } \\
\text { tions }\end{array}$ \\
\hline & & Midazolam & Metabolism (ind) & Monitor midazolam therapeutic effects \\
\hline & & Dapsone & Metabolism (ind) & $\begin{array}{l}\text { Monitor for dapsone therapeutic effects and methemoglobine- } \\
\text { mia }\end{array}$ \\
\hline & \multirow[t]{4}{*}{ Erythromycin } & Amlodipine & Metabolism (inh) & Consider an alternative, monitor toxic effects \\
\hline & & Carbamazepine & Metabolism (inh) & Consider an alternative, monitor toxic effects \\
\hline & & Dexamethasone & Metabolism (inh) & Monitor corticosteroids toxic effects \\
\hline & & Prednisolone & Metabolism (inh) & Monitor corticosteroids toxic effects \\
\hline & Posaconazole & Midazolam & Metabolism (inh) & Consider an alternative, monitor toxic effects \\
\hline & Isoniazid & Metoprolol & Metabolism (inh) & Consider an alternative, monitor response \\
\hline & Valganciclovir & Lamivudine & Additive & Monitor hematologic toxicity \\
\hline & Clarithromycin & Midazolam & Metabolism (inh) & Consider an alternative, monitor for toxic effects \\
\hline \multirow{14}{*}{$\begin{array}{l}\text { Central nerv- } \\
\text { ous system } \\
\text { agents }\end{array}$} & \multirow[t]{5}{*}{ Carbamazepine } & Phenytoin & Metabolism (ind) ${ }^{b}$ & Monitor for phenytoin/carbamazepine serum concentrations \\
\hline & & Clonazepam & Metabolism (ind) & Consider an alternative \\
\hline & & Warfarin & Metabolism (ind) & Monitor therapeutic effects \\
\hline & & Citalopram & Metabolism (ind/inh) ${ }^{b}$ & $\begin{array}{l}\text { Monitor citalopram therapeutic effects/carbamazepine toxic } \\
\text { effects }\end{array}$ \\
\hline & & Fluvoxamine & Metabolism (ind/inh) & $\begin{array}{l}\text { Monitor fluvoxamine therapeutic effects/carbamazepine toxic } \\
\text { effects }\end{array}$ \\
\hline & \multirow[t]{2}{*}{ Imipramine } & Metoprolol & Metabolism (inh) & Consider an alternative, monitor response \\
\hline & & Citalopram & Metabolism (inh) ${ }^{b}$ & $\begin{array}{l}\text { Consider an alternative, monitor toxic effects of imipramine/ } \\
\text { citalopram }\end{array}$ \\
\hline & \multirow{2}{*}{$\begin{array}{l}\text { Quetiapine } \\
\text { fumarate }\end{array}$} & Haloperidol & Additive & Avoid combination \\
\hline & & $\begin{array}{l}\text { Carbidopa and } \\
\text { levodopa }\end{array}$ & Antagonistic & Consider an alternative \\
\hline & Phenytoin & Amlodipine & Metabolism (ind/inh) ${ }^{b}$ & Monitor amlodipine therapeutic effects/phenytoin toxicity \\
\hline & \multirow[t]{3}{*}{ Indomethacin } & Acetylsalicylic acid & Additive & Monitor bleeding, avoid regular use of indomethacin \\
\hline & & Cyclosporine & Additive & Consider an alternative, monitor nephrotoxicity \\
\hline & & Furosemide & Antagonistic & Monitor therapeutic effect \\
\hline & Valproic acid & Lorazpam & Metabolism (inh) & Monitor lorazepam toxic effects \\
\hline
\end{tabular}


Table 4 continued

\begin{tabular}{|c|c|c|c|c|}
\hline Drug classes & $\begin{array}{l}\text { Precipitant } \\
\text { drugs }^{\text {a }}\end{array}$ & Object drugs $^{\mathrm{a}}$ & Mechanisms & Recommendations \\
\hline \multirow{6}{*}{$\begin{array}{l}\text { Electrolytic, } \\
\text { caloric, and } \\
\text { water bal- } \\
\text { ance }\end{array}$} & $\begin{array}{l}\text { Sodium polysty- } \\
\text { rene sulfate }\end{array}$ & Calcium carbonate & Antagonistic & Separate doses by 2 or more hours, monitor metabolic alkalosis \\
\hline & Zinc sulfate & Ofloxacin & Absorption & Separate doses by 2 or more hours \\
\hline & $\begin{array}{l}\text { Magnesium } \\
\text { sulfate }\end{array}$ & Ciprofloxacin & Absorption & Separate doses by 2 or more hours \\
\hline & \multirow{3}{*}{$\begin{array}{l}\text { Calcium carbon- } \\
\text { ate }\end{array}$} & Isoniazid & Absorption & Separate doses by 2 or more hours \\
\hline & & Levofloxacin & Absorption & Separate doses by 2 or more hours \\
\hline & & Mycophenolate & Absorption & Separate doses by 2 or more hours \\
\hline \multirow{5}{*}{$\begin{array}{l}\text { Autonomic } \\
\text { drugs }\end{array}$} & \multirow[t]{4}{*}{ Atracurium } & Methylprednisolone & Additive & Monitor neuromuscular adverse effects \\
\hline & & Prednisolone & Additive & Monitor neuromuscular adverse effects \\
\hline & & Dexamethasone & Additive & Monitor neuromuscular adverse effects \\
\hline & & Hydrocortisone & Additive & Monitor neuromuscular adverse effects \\
\hline & Cisatracurium & Prednisolone & Additive & Monitor neuromuscular adverse effects \\
\hline \multirow{4}{*}{$\begin{array}{l}\text { Cardiovascular } \\
\text { drugs }\end{array}$} & Amiodarone & Digoxin & Excretion & Reduce digoxin dosage, monitor serum concentration \\
\hline & & Metoprolol & Metabolism (inh) & Consider an alternative, monitor response \\
\hline & Gemfibrozil & Atorvastatin & Metabolism (inh) & Avoid combination \\
\hline & Metoprolol & Epinephrine & Additive & Monitor pressor effects of epinephrine \\
\hline \multirow{3}{*}{$\begin{array}{l}\text { Blood forma- } \\
\text { tion, coagula- } \\
\text { tion, ...... }\end{array}$} & $\begin{array}{l}\text { Acetylsalicylic } \\
\text { acid }\end{array}$ & Warfarin & Additive & Monitor bleeding \\
\hline & Ferrous sulfate & Ofloxacin & Absorption & Separate doses by 4 or more hours \\
\hline & & Levothyroxine & Absorption & Separate doses by 2 or more hours \\
\hline \multirow[t]{2}{*}{$\begin{array}{l}\text { Gastrointestinal } \\
\text { drugs }\end{array}$} & Pantoprazole & Itraconazole & Absorption & $\begin{array}{l}\text { Administer itraconazole with an acidic beverage, monitor } \\
\text { response }\end{array}$ \\
\hline & Ranitidine & Itraconazole & Absorption & $\begin{array}{l}\text { Administer itraconazole with an acidic beverage, monitor } \\
\text { response }\end{array}$ \\
\hline \multirow{2}{*}{$\begin{array}{l}\text { Hormones and } \\
\text { synthetic } \\
\text { substitutes }\end{array}$} & Dexamethasone & Clarithromycin & Metabolism (ind/inh) ${ }^{b}$ & $\begin{array}{l}\text { Consider alternative antimicrobial therapy/monitor for dexa- } \\
\text { methasone toxic effects }\end{array}$ \\
\hline & & Itraconazole & Metabolism (ind) & Avoid combination, monitor for therapeutic effects \\
\hline \multirow[t]{2}{*}{ Miscellaneous } & Cyclosporine & Atorvastatin & Metabolism (inh) & Avoid combination \\
\hline & & Mycophenolate & Excretion & Monitor mycophenolate dosing and response to therapy \\
\hline
\end{tabular}

inh Inhibition, ind induction

a The precipitant drug causes the interaction and the object drug is affected by the interaction

b Both medications act on each other

GI bleeding compared with H2RA or placebo in ICU patients [34], an international survey of 97 units in 11 countries showed that PPIs were the most common stress ulcer prophylaxis agent, used in $66 \%$ of ICUs (64/97) [35]. Using oral PPIs instead of intravenous injection could be a useful strategy to prevent pDDIs.

In hormone and synthetic substitutes, an important interaction occurred between dexamethasone and CYP3A substrates (clarithromycin and itraconazole). Dexamethasone as a strong CYP3A inducer may decrease the serum concentration and therapeutic effectiveness of these medications [36]. Alternative antimicrobial therapy (when possible) and monitoring patients closely for evidence of diminished clinical response are important preventive measures.

Immunosuppressive drugs classified as miscellaneous therapeutic agents can lead to life-threatening pDDIs in transplant subjects. Cyclosporine has been shown to reduce the AUC of mycophenolic acid (MPA) by inhibiting its glucuronide conjugate mycophenolic acid glucuronide conjugate (MPAG) excretion into the bile. Changes in mycophenolate dosage may be required in cases of concurrent cyclosporine starting, stopping, or dose changing [37]. Studies have shown that the concurrent use of cyclosporine with atorvastatin can increase systemic exposure to the statins and related toxicities such as myopathy and rhabdomyolysis. A statin that is less sensitive to this interaction (e.g., pravastatin or fluvastatin) or an alternative type of LDL-lowering medication should be considered $[37,38]$.

Several limitations could be considered for the current study. Age is an important factor for DDIs prevalence, and a positive relationship has been found between age and the number of DDIs [9]. The median age of patients 
in this study (48 years) was lower than that of western countries. Differences between the ICUs in developing and advanced countries could explain this discrepancy. For an appropriate interpretation and application of the ICU data, the diversity among countries including funding, laws, cultural values, and disease prevalence should be considered $[39,40]$. In the current study, tracheal stenosis and empyema were the most common respiratory system diseases that lead to ICU admissions. Therefore, several reasons (prevalence of diseases, culture, laws, and life expectancy) may play a role in the low median age of patients in the current study.

The second limitation is using one DDI database that could limit the number of pDDIs. Lexi-Interact is a commonly used resource providing detailed DDI information and was available in the studied hospital. This database with a documentation rating that is useful in recognizing well-documented interactions would limit clinical repercussions. Using different software at the same time, however, could lead to more accurate results [41]. The setting of the current study, the cardiothoracic ICU of a pulmonary referral hospital, is another limitation. A list of drugs approved by hospital formulary committee is specific for an ICU setting. However, commonly used drugs in ICUs are usually considered in critical care drug handbooks and manuals [42, 43]. Therefore, reported interactions related to common drugs could be generalized to other ICUs. The interactions caused by specific medications prescribed in a specialized ICU could also be identified and prevented by similar studies.

\section{Conclusions}

Due to the high prevalence of pDDIs in the ICU setting, the authors recommend more specialized studies on clinically significant pDDIs and continued education based on the results. Highlighting important drug classes and specific medications responsible for the interactions in different settings could increase the knowledge and awareness of clinicians to improve patient safety.

\section{Abbreviations \\ ICU: intensive care unit; DDIs: drug-drug interactions; pDDIs: potential drug- drug interactions; CNS: central nervous system; PPIs: proton pump inhibitors; $\mathrm{H}_{2} \mathrm{RAs}$ : histamine-2 receptor antagonists; SRMD: stress-related mucosal dam- age; Gl: gastrointestinal; MPA: mycophenolic acid; MPAG: mycophenolic acid glucuronide conjugate.}

\section{Authors' contributions}

SB and BF designed the study and collected the data. SB and MA managed the database, analyzed the data, and prepared the manuscript. All authors read and approved the final manuscript.

\section{Author details}

${ }^{1}$ Virology Research Center, National Research Institute of Tuberculosis and Lung Diseases (NRITLD), Shahid Beheshti University of Medical Sciences, Tehran, Iran. ${ }^{2}$ Tracheal Diseases Research Center, National Research Institute of Tuberculosis and Lung Diseases (NRITLD), Shahid Beheshti University of Medical Sciences, Tehran, Iran.

\section{Acknowledgements}

The authors would like to thank Asghar Khosh Akhlagh, RN, for assistance with data extraction and chart review as well as National Research Institute of Tuberculosis and Lung Diseases (NRITLD), for funding support.

\section{Competing interests}

The authors declare that they have no competing interests.

Received: 19 March 2015 Accepted: 9 November 2015

Published online: 24 November 2015

\section{References}

1. Smithburger PL, Kane-Gill SL, Seybert AL. Drug-drug interactions in the medical intensive care unit: an assessment of frequency, severity and the medications involved. Int J Pharm Pract. 2012;20:402-8.

2. Kane-Gill S, Weber RJ. Principles and practices of medication safety in the ICU. Crit Care Clin. 2006:22:273-90.

3. May FE, Stewart RB, Cluff LE. Drug interactions and multiple drug administration. Clin Pharmacol Ther. 1977;22:322-8.

4. Zarowitz BJ. Pharmacologic principles. In: Ayres SM, Grenvik A, Holbrook PR, hoemaker WC, editors. Textbook of critical care. 3rd ed. Philadelphia: W.B. Saunders; 1995. p. 1141-50.

5. Zagli G, Tarantini F, Bonizzoli M, Di Filippo A, Peris A, De Gaudio AR, et al. Altered pharmacology in the intensive care unit patient. Fundam Clin Pharmacol. 2008;22:493-501.

6. Grizzle AJ, Mahmood MH, Ko Y, Murphy JE, Armstrong EP, Skrepnek GH, et al. Reasons provided by prescribers when overriding drug-drug interaction alerts. Am J Manag Care. 2007;13:573-8.

7. Becker ML, Caspers PW, Kallewaard M, Bruinink RJ, Kylstra NB, Heisterkamp S, et al. Determinants of potential drug-drug interaction associated dispensing in community pharmacies in the Netherlands. Pharm World Sci. 2007;29:51-7.

8. Sweilehe WM, Sawalhae AF, Jaradate NA. Extent of potential drug interactions among patients receiving anti-hypertensive medications. Saudi Med J. 2005;26:548-52.

9. Ismail M, Iqbal Z, Khattak MB, Khan MI, Arsalan H, Javaid A, et al. Potential drug-drug interactions in internal medicine wards in hospital setting in Pakistan. Int J Clin Pharm. 2013;35:455-62.

10. Smithburger PL, Kane-Gill SL, Seybert AL. Drug-drug interactions in cardiac and cardiothoracic intensive care units: an analysis of patients in an academic medical centre in the US. Drug Saf. 2010;33:879-88.

11. Askari M, Eslami S, Louws M, Wierenga PC, Dongelmans DA, Kuiper RA, et al. Frequency and nature of drug-drug interactions in the intensive care unit. Pharmacoepidemiol Drug Saf. 2013;22:430-7.

12. Reis AM, Cassiani SH. Prevalence of potential drug interactions in patients in an intensive care unit of a university hospital in Brazil. Clinics (Sao Paulo). 2011;66:9-15.

13. Hammes JA, Pfuetzenreiter F, Silveira FD, Koenig A, Westphal GA. Potential drug interactions prevalence in intensive care units. Rev Bras Ter Intensiva. 2008;20:349-54

14. Uijtendaal EV, van Harssel LL, Hugenholtz GW, Kuck EM, Zwart-van Rijkom JE, Cremer OL, et al. Analysis of potential drug-drug interactions in medical intensive care unit patients. Pharmacotherapy. 2014;34:213-9.

15. Up-to-date[online]. Lexi-interact online. http://www.uptodate.com/ crlsql/interact/frameset.jsp. Accessed 15 Jan 2015.

16. McEvoy GK, Snow ED (editors). AHFS: drug information. Bethesda: American Society of Health-System Pharmacists; 2012.

17. World Health Organization. ICD-10 classifications of mental and behavioural disorder. Geneva: Clinical Descriptions and Diagnostic Guidelines; 2015.

18. Martinbiancho J, Zuckermann J, Dos Santos L, Silva MM. Profile of drug interactions in hospitalized children. Pharm Pract (Granada). 2007:5:157-61.

19. Magnus D, Rodgers S, Avery AJ. GPs' views on computerized drug interaction alerts: questionnaire survey. J Clin Pharm Ther. 2002;27:377-82. 
20. Pereira JM, Paiva JA. Antimicrobial drug interactions in the critically ill patients. Curr Clin Pharmacol. 2013;8:25-38.

21. Baniasadi S, Fahimi F, Shalviri G. Developing an adverse drug reaction reporting system at a teaching hospital. Basic Clin Pharmacol Toxicol. 2008;102:408-11.

22. Islahudin F, Ong HY. Appropriate vancomycin use in a Malaysian tertiary hospital based on current HICPAC recommendations. J Infect Dev Ctries. 2014;8:1267-71.

23. Del Rosso JQ. Oral antibiotic drug interactions of clinical significance to dermatologists. Dermatol Clin. 2009;27:91-4.

24. Mignat C. Clinically significant drug interactions with new immunosuppressive agents. Drug Saf. 1997;16:267-78.

25. Smithburger PL, Seybert AL, Armahizer MJ, Kane-Gill SL. QT prolongation in the intensive care unit: commonly used medications and the impact of drug-drug interactions. Expert Opin Drug Saf. 2010;9:699-712.

26. John LJ, Devi P, John J, Arifulla M, Guido S. Utilization patterns of central nervous system drugs: a cross-sectional study among the critically ill patients. J Neurosci Rural Pract. 2011;2:119-23.

27. Lima RE, De Bortoli Cassiani SH. Potential drug interactions in intensive care patients at a teaching hospital. Rev Lat Am Enfermagem. 2009;17:222-7.

28. Lexicomp online ${ }^{\circledR}$, Carbamazepine: drug information. Hudson: LexiComp, Inc.; 2015.

29. Kindler CH, Verotta D, Gray AT, Gropper MA, Yost CS. Additive inhibition of nicotinic acetylcholine receptors by corticosteroids and the neuromuscular blocking drug vecuronium. Anesthesiology. 2000;92:821-32.

30. Murray MJ, Cowen J, DeBlock H, Erstad B, Gray AW Jr, Tescher AN, Task Force of the American College of Critical Care Medicine (ACCM) of the Society of Critical Care Medicine (SCCM), American Society of HealthSystem Pharmacists, American College of Chest Physicians, et al. Clinical practice guidelines for sustained neuromuscular blockade in the adult critically ill patient. Crit Care Med. 2002;30:142-56.

31. Lexicomp online ${ }^{\circledR}$, Amiodarone: drug information. Hudson: Lexi-Comp, Inc.; 2015.
32. Brett S. Science review: the use of proton pump inhibitors for gastric acid suppression in critical illness. Crit Care. 2005;9:45-50.

33. Johnson MD, Hamilton CD, Drew RH, Sanders LL, Pennick GJ, Perfect JR. A randomized comparative study to determine the effect of omeprazole on the peak serum concentration of itraconazole oral solution. J Antimicrob Chemother. 2003;51:453-7.

34. Krag M, Perner A, Wetterslev J, Møller MH. Stress ulcer prophylaxis in the intensive care unit: is it indicated? A topical systematic review. Acta Anaesthesiol Scand. 2013;57:835-47.

35. Krag M, Perner A, Wetterslev J, Wise MP, Borthwick M, Bendel S, et al. Stress ulcer prophylaxis in the intensive care unit: an international survey of 97 units in 11 countries. Acta Anaesthesiol Scand. 2015;59:576-85.

36. Frew JW. The clinical significance of drug interactions between dermatological and psychoactive medications. Dermatol Ther. 2014;27:1-11.

37. Manitpisitkul W, McCann E, Lee S, Weir MR. Drug interactions in transplant patients: what everyone should know. Curr Opin Nephrol Hypertens. 2009:18:404-11.

38. Amundsen R, Christensen H, Zabihyan B, Asberg A. Cyclosporine A, but not tacrolimus, shows relevant inhibition of organic anion-transporting protein 1B1-mediated transport of atorvastatin. Drug Metab Dispos. 2010;38:1499-504.

39. Wunsch $\mathrm{H}$, Rowan KM, Angus DC. International comparisons in critical care: a necessity and challenge. Curr Opin Crit Care. 2007;13:725-31.

40. Murthy $\mathrm{S}$, Wunsch $\mathrm{H}$. Clinical review: international comparisons in critical care-lessons learned. Crit Care. 2012;16:218.

41. Oshikoya KA, Oreagba IA, Ogunleye OO, Lawal S, Senbanjo IO. Clinically significant interactions between antiretroviral and co-prescribed drugs for HIV-infected children: profiling and comparison of two drug databases. Ther Clin Risk Manag. 2013;9:215-21.

42. Paw H, Shulman R. Handbook of drugs in intensive care: an A-Z guide. 4th ed. New York: Cambridge University; 2010.

43. Young P. Intensive care unit drug manual, 2nd ed. Wellington, New Zealand; 2013

\section{Submit your manuscript to a SpringerOpen ${ }^{\circ}$ journal and benefit from:}

- Convenient online submission

- Rigorous peer review

- Immediate publication on acceptance

- Open access: articles freely available online

- High visibility within the field

- Retaining the copyright to your article

Submit your next manuscript at $>$ springeropen.com 